\title{
Obstetricians and pregnant women from Formiga's town, in Minas Gerais State, Brazil. Deciding what kind of labor to be held
}

\author{
Heslley Machado Silva1, Angélica Rodrigues da Costa ${ }^{2}$, Radassa de Avelar Nogueira Herculano ${ }^{3}$ \\ ${ }^{1}$ Department of University Center, UNIFOR/MG and Itaúna’s University/MG, Itaúna, Brazil \\ ${ }^{2}$ Department of University Center, UNIFOR/MG_FAPEMIG, University Center of UNIFOR/MG, Formiga, Brazil \\ ${ }^{3}$ Department of Itaúna’s University/MG, Itaúna, Brazil \\ Email: heslley@uniformg.edu.br
}

Received 28 August 2012; revised 30 September 2012; accepted 9 October 2012

\begin{abstract}
The decision of what kind of labor that should be held is intermittently generating a great debate in Brazil. The growth in the number of cesarean sections has raised worries in some of the involved sectors of the society. It was proposed to investigate the factors which lead the women to take this decision, trying to understand the principle involved. A bibliographic review about the subject was made. The research happened in the town of Formiga, where some data were collected in two hospitals-public and private -about the number of labors during two months. Subsequently, the obstetricians and a group of pregnant women were submitted to a questionnaire, the answers were compiled and transformed into graphs which were analyzed. Finally, the data were compared with the related literature. The number of cesarean sections in the town was above the standard recommended. According to the obstetricians, the main reason would be the preference of the pregnant women, fact which was not confirmed by them, that discrepancy was confirmed by the literature. The level of information about the clinical indications for the type of labor was considered satisfactory by the doctors and the pregnant women, data contestable by the academics. The fear and the pain were identified by obstetricians and pregnant women as a predominant factor for the preference of cesarean sections, provided that, according to the literature, shows the precariousness of information for pregnant women about the normal birth. Another important data is that the doctors can have an important role in the kind of labor to be made. According to the obstetricians, their role would be very limited, but according to some pregnant women, they did trust in the doctors which should be the ideal labor for them. The analysis of most of the data collected shows a discre-
\end{abstract}

pancy between the information of pregnant women and obstetricians. Both sides involved in the issue do not admit as responsible for the elevate number of cesarean sections, so, some new approaches are needed for analysis. This analysis and diagnosis indicate the next step of the research: the supervision of the pregnant women, since the beginning of the gestation until the birth, trying to figure out the real factors which lead them to decide what kind of delivery should be taken.

Keywords: Birth; Public Health; Pregnant Women; Natural Childbirth; Cesarean Section; Obstetrics

\section{INTRODUCTION}

The decision on what kind of labor to be made is fount of an intermittent discussion in Brazil. The cesarean section as a surgical intervention with the proposal of saving lives, in certain circumstances [1,2] has been dizzily growing and according to the World Health Organization (WHO), without justifiable cause [3]. This reality has called the attention of national and international public organizations, as well as the academic section, once the raise of the cesarean labor doesn't follow the decrease in maternal and newborn taxes of mortality $[3,4]$.

During the last decades, it was noticed that in many countries of the world a raise in the percent of cesarean sections over natural birth $[2,5,6]$. The cesarean section rates reach 26\% in the United States; 21.3\% in England; $23.9 \%$ in North Ireland and 19\% in Canada [7].

In Latin America the rates of cesarean section in 1960 was between $2 \%$ and $5 \%$, and in the end of 1980 decade was in between $30 \%$ and $33.4 \%$. In this context is highlighted the incidence of those kind on labor in Brazil [8]. Data related to 1990 decade reveal that in Brazil the percentage was $36 \%$ and the highest taxes were in Sao Paulo (52\%) and at Middle-West Region (49\%) while 
the lowest ones were in Northeast (20\%) and North region $(25 \%)$. The cesarean section is more frequent in the urban area $(41.8 \%)$ than the rural area $(20.1 \%)$ [9], occurring more in private hospitals, in regions and patients with higher income, being then pregnant women in better social and health conditions, so with less risk in the procedures that evolve the gestation [10].

As the trend of the growing number of cesareans has continued through the 1990s, the proportion of cesarean sections expected for the next years (2000) would be of almost 60 for 100 births [11]. In the year of 2002, 38.7\% of births in Brazil occurred by cesarean [12].

The reasons for this expressive number of cesarean sections are diverse and have been built through the last decades in the country. Initially, in 1070's decade, it was attributed by the higher remuneration of cesarean, by the National Institute of Medical Assistance of Social Foresight (INAMPS) and by the non-coverage of analgesia in vaginal delivery. But the growing trend is not inverted when the INAMPS corrects this distortion [13].

Another hypothesis is that it would have a pathological conception of labor in the training of the medical area professionals, compared to the sophisticated technology in the surgical procedure. Further that, there would be a devaluation of learning assistance to the normal delivery [13].

Regarding this last possibility, it also would have a preference for the programmed intervention, by the organized obstetric attention and by the insecurity of the doctor, coming from an insufficient training in the diverse variation that can occur during the curse of normal delivery [14]. These high rates also could be explained by the performance of tuballigation concomitant with cesarean [15].

Social-cultural factors must be considered, they would lead the pregnant patients to ask for cesarean section for many reasons including: the fear of the pain in the moment of birth, as the same time as the envision of the cesarean without any pain because of the analgesia; the maintenance of the anatomy and physiology of the vagina and perineum intact, preserving the quality of vaginal intercourse; the belief that normal delivery has more risks than cesarean section and finally, the idea that the surgical intervention would be the most modern, advanced way to have child in relation to the delay of normal birth [1,10].

Facing this reality, the Health Ministry of Brazil has been developing since 1997, public polices which aims the reduction of the prevalence of cesarean over normal delivery. However, this brazilian public policy in force, which aims to encourage the normal delivery in the federal, state and municipal levels, failed when trying to stop the advance in number of cesarean labor verified in the last decades.
According to a survey conducted by the Ministry of Health and the National Agency of Supplementary Health (ANS), in 2006 the SUS (Single Health System) recorded a $26 \%$ rate of cesarean sections, while in the supplementary section, this proportion was of $80 \%$, making a national average of $43 \%$ [16]. The study also revealed that the southeast keeps assuming the highest levels, in contrast to what happens in the north region, where there are a higher number of normal deliveries. These information shows that Brazil is one of the countries with higher levels of cesarean sections, while that is far beyond the recommended by WHO [16].

Due to this fact, in May 2008, these two agencies have launched a national campaign "Normal Birth: let the life happen naturally", which was directed to physicians, women and partners, security health plans operators and to the whole society [16]. The intention was to reduce, until the year of 2011, the taxes of cesarean sections to $60 \%$ in the private area and to $25 \%$ at the public maternity hospitals [17]. Several authors keep finding in their works really high rates of cesarean section in the Supplemental Health System, values around 90\% [18].

In this context, the study has the objective of realizing the diagnosis overview of both types of deliveries conducted in two hospitals of the referred city and investigate how each one of the agents involved (obstetricians and pregnant women) participates of the decision of the type of labor to be made. The majority of researches about the theme discuss the reality in the large urban area. Therefore, it was tried to feed this discussions in local data and analysis, to refer the inner cities, as the city of Formiga-MG.

\section{METHODS}

To perform the prospective work, it was initially used the exploratory survey as the mechanism of delimitation and knowledge of the object to be investigated. It was researched an extensive literature as a way of comparison parameter and to complement the state of art of the survey related to the types of deliveries made in Brazil. To understand the overall picture of the types of deliveries conducted in the city of Formiga, it was followed weekly during two months (September and October of 2005) the functioning of maternity hospitals in the city, checking the medical records of the pregnant women and registering the type of delivery, and if this one was private or public.

As a second step of this exploratory research, the obstetricians of Formiga's city were interviewed-with the exception of one by the difficulty of access, making a total of seven doctors by a previously elaborates questionnaire (September of 2007). The questionnaire applied to the doctors had six questions that, despite being objective, should be justified. To make the data collection 
together with the doctors, it was made a visit schedule to their offices adapted to their availability. Once scheduled, the meeting lasted an average of thirty minutes and so allowed, beyond the written information, also obtaining clarifications of those health professionals points of view related to the preference of the labor type and of what happens during the medical practice. It is important to highlight that the questionnaires were filled by the doctors with the presence of the interviewer, except for one.

Subsequently, a new step was performed with a questionnaire submitted to the pregnant women, who were selected randomly (February of 2008). This questionnaire contained the name initials, the age, the number of children, and the education level and there were a total of nine questions, which one was subjective and eight were objective and also needed to be justified.

It was sought the consent of the respondents, as participants of the research, without mentioning their identity in data disclosure, being given the option of anonymity in the answers from the questionnaires. The research was submitted to the Ethics Committee of the core research from UNIFOR/MG, which approved. The term of free and clarified consent was presented at the beginning of the survey. It was solicited to the obstetricians and the pregnant women the participation in the research. It was also intended not to occur judgment of values about the answers, used only for comparison and discussion with the relevant literature.

The data collected in hospitals, with the doctors and the pregnant women were analyzed and interpreted through simple spreadsheet in Microsoft Office Excel, being therefore transformed into graphs. This choice is based on the affirmation of Callegari-Jacques [19]: "The graphic representation gives a more immediate vision on how individuals are distributed in the different values of variable". All these information collected quantitative and qualitative, hospitals, obstetricians and pregnant women, were analyzed, compared, discussed and confronted with the authors who discuss this theme through the extensive bibliographic review.

\section{RESULTS}

Referring to the types of delivery conducted in the two municipal hospitals in the study, it was in evidence that in the private maternity hospital there was a performance of cesarean section in the totality of births (100\%). In the other hospital, which includes the private and public systems, it was found approximate rates, but still with a predominance of cesarean delivery (51\%). In this last one, it could be observed that separately, in the public delivery, there was prevalence of normal birth (64\%), and in the private delivery the proportion of cesarean section reached $95 \%$.
In an interview, most of the obstetricians (86\%) affirmed that, in practice, the numbers of cesarean sections are above of the recommended and, according to them, the main reason would be the preference of the women, highlighting the existence of two realities: the pregnant women from SUS and the ones who are private/insured. The main divider would be the non-covet of analgesia of normal birth by SUS that, according to doctors, the hospital receives a negligible value for it and allows only $30 \%$ of cesarean sections in the total of labors in the hospital. This evident division of treatment between private and public system is portrayed by doctor $\mathrm{B}$ : "The cesarean section by SUS is as expected, but in private and insured is beyond expected, once these pregnant women require the $C$-section. There is anesthesia for normal delivery, but this one is only being paid by the ministry of health recently and the amount does not cover the expenses, so the majority of SUS' patients doesn't get the anesthesia and complain a lot of labor pains and the delay of the birth". In contrast, the pregnant women who are health insured or private seem not to allow another possibility besides cesarean section, therefore it would fit to obey, as reported by the doctor A: "In the case of private and health insured patients, $90 \%$ choose for cesarean". Some doctors have shown a different view, which shares the responsibilities related to the overwhelming number of cesarean sections, presenting a complex picture, which can be portrayed through the speech of doctor C: "The anxiety of patients is because they fear the pain and the unexpected, and they also are misguided; it exists the culture that the natural birth will damage the perineum area and this is not the truth; the fear of the pain is unfortunately associated to the anesthesia which SUS does not cover it and $80 \%$ of the patients do not have a health insurance and neither conditions to afford; the doctor himself has a share of blame because of the lack of time, the cost reasons and obstetricians' experiences".

The majority of the obstetricians (86\%), affirms that the pregnant women understand well the indication for cesarean section, once they explain the advantages and disadvantages, but still, the pregnant women private or health insured deny the indication of natural birth. There is no contradiction in the level of information, as showed by the doctor C: "They are well oriented by me, I explain the positive and negative issues of cesarean section”. In general, what most contributes for the preference of cesarean delivery is the fear of normal birth associated to the pain, the delay, the unexpected and the family influence. Therefore, information regarding risks and advantages of each type of delivery seem to be effected as mentioned by doctor B: "In prenatal, we explain the indications and we are open to clarify the doubts". Despite this apparently farmable context, as long as the level of 
information, the general picture seems not to change, as it can be confirmed by the doctor B: "They understand the indication, but still refuse the vaginal delivery".

The large portion of the obstetricians (75\%) revealed that tries to argue in favor of normal delivery, but according to them, if they insist they have the risk of losing the patient who changes the professional. This dilemma can be reported by doctor D: "Patients who have all the condition for vaginal delivery and choose for cesarean section, if you deny doing it, they may even look for another doctor".

More than half of the obstetricians (57\%) affirm that there is difficulty in communication between doctors and patients in the decision of what kind of labor and that, many times, the relation can be broken. Even with all the information that the prenatal monitoring could provide, many times the dialogue is in vain, as noticed by the doctor B: "In the Brazilian population is rooted in the idea that natural birth is very painful, suffered and slow, which difficulties a lot our arguments". The communication collides in a serie of preconceived ideas, turning the arguing unsuccessful, as reported by doctor C: "The patient can have a defined posture because of convictions which she judges right or by the influence of third ones with negative experiences in relation of normal delivery. This and other factors can even shake the relationship between doctor and patient".

Facing this difficulty of dialogue between doctor and patient and the risk of losing the patient for another professional, the obstetricians were divided in the opinion about being or not determinant in the type of labor to be performed. A considerable proportion (43\%) affirmed that sometimes they are determinants and the minority (14\%) says not to be. The rest (43\%) who believes being important, mentioned the right of choice of the private/ health insured pregnant women by the type of labor. This dichotomy between defining the type of labor, based on their training and experience, at the same time hearing the patient, specially the private/health insured ones, is highlighted by doctor $\mathrm{C}$, when affirming that: "The doctor is responsible for the patient. The best procedure for the patient should be defined by the doctor who is technically prepared. But the private patients have the right to opt for the type of treatment, as long as they sign a pre-informed consent."

The pregnant women who participated in the research had between 19 and 34 years, presenting an average of 26, 8 years. Regarding their level of education, more than half (51\%) completed the elementary school. Considering the number of pregnancies, a considerable proportion (43\%) were in their first one, as long as the rest had already a child (33\%), three children (8\%), four children (8\%) and five children (8\%).

The analysis of information gathered with the pregnant women revealed that the majority of them (75\%) had already decided what type of labor to be performed. Among these, more than half (67\%) had decided by normal birth as their preference, while the remaining ones (33\%) decided by cesarean section. The preference for normal delivery was justified by the faster recovery, while the choice for cesarean section was based on the fear of normal birth related to the pain. Although these data do not materialize in a larger number of natural births, the speeches of some pregnant women like R. C. N. and A. F. A. reveal, respectively, a conscious desire of achieving natural childbirth: "It's less traumatic for me and for the baby, is a natural method and the recovery is faster than the cesarean section" and "The child is already in the position for normal delivery and everything seems that it is what is going to be, even because I prefer".

As for being or not properly informed about the types of labor, the larger part of the pregnant women (92\%) answered yes and obtaining information occurred through the family (33\%), the obstetrician (28\%), magazines-TVinternet (22\%) and others (17\%). The relevance given to information passed by the closest people, especially by family, is showed when V.S.C. affirms that "I search for information with my sisters who are already mothers".

When the pregnant women were questioned about how the evaluate the possibility of natural birth being performed, more than half (59\%) answered with fear, mainly because of the pain. This extreme fear is noted at the speech of S.E.C. when affirming that: "I am afraid of hurting a lot”. The sources of information for most of the pregnant women relate the normal birth to the pain, as it can be noticed when V.S.C. mentions that: "Because of the pain which a lot of women talk about ..." It builds a picture where the desire for normal birth is overlapped by a mixture of ignorance associated to sources of information loaded with repulse to the possibility of pain, as it is noticed when A.F.A. tells that: "Although I prefer the normal birth, I fear because I do not know about the pain, how is the pain". An important portion (33\%) sees the possibility of having a natural birth peacefully and minority $(8 \%)$ scored another answer. The pregnant women who consider the possibility of doing a normal delivery calmly justified that the pain is inherent in the process of gestation.

In sequence the pregnant women received the same type of questioning, but about the possibility of doing a cesarean section. More than the half of the pregnant women (59\%) answered with security, especially because of the anesthesia that reliefs the pain in the moment of labor. This vision can be noticed by M.D.L.: "Because of the anesthesia which reliefs the pain". Some considered the C-section more efficient, practical, so they would be free from the pain as showed by V.C.F.: "Besides being faster, there is no pain in the moment of the labor, only after a 
few days”. A considerable portion (33\%) answered with fear and the minority scored another answer. The report of fear of cesarean labor was associated with the problems related to anesthesia, excessive bleeding and the complicated post-operation.

More than the half of pregnant women interviewed (58\%) affirmed already have received influence in order to decide the type of labor, what happened by family and friends, while the rest (42\%) denied any influence received.

When being questioned about in who they trust the most to assist in the decision on the type of labor, the most part of the pregnant women (92\%) pointed the obstetrician and the minority (8\%) trusts themselves to decide the type of delivery. And, again, almost the totality of the pregnant women (92\%) answered that is in the hand of the obstetrician that is the final decision for the type of labor to be performed, while the minority (8\%) believes that the final decision is with them. The voice of the expressive majority pointing the doctor as having the final decision is related in the speech of the pregnant women S.E.C.: "Because only the gynecologist knows what is the best option for the mother and the baby and what type of labor which can be performed".

\section{DISCUSSION}

Regarding the overview on the types of labor conducted, the city of Formiga-MG shows the typical Brazilian pattern, a high number of cesarean sections mainly in the private labors. According to the opinion of the majority of doctors in this research, the high taxes of C-sections are due to the preference of many women, doctors $\mathrm{A}$ and D show this perception related to this question respectively in the following lines "Some pregnant women already come determined with the idea" and "It is not always that they accept your indication". It could be found together with the pregnant women that other factors can be decisive in an inner city, like the relevant influence from family and known people, as related by doctor C: " ... because of the influence of third ones with negative experiences relates to normal birth” and referred by pregnant women A.F.A when saying that "I search to keep myself informed with more experienced people, who already are mothers".

The alternative between the types of labor seems to be linked to certain groups of women, being the decision possibly associated to economic, social and cultural factors $[18,20]$. The claim that cesarean delivery is comprehensive in certain groups of women follows consensus in the literature, while the SUS has represented, at least apparently, a difficulty for the realization [21-23]. However, there is the need to more detailed approaches which explain better this situation $[21,23]$.
The research realized with the pregnant women showed that more than half of the women who had already decided the type of labor had the preference for normal delivery, mainly because of the faster recovery. Some pregnant women could express clearly this position like shown by S.A.S.C.: "Because the mother and the baby suffer less, everything which is natural is better". Therefore, the argument that cesarean section is the best option, considering being the preference of many women and these have the right to decide, seems not to correspond with the reality, indicating a failure in communication between physicians and pregnant women [24,25].

According to large portion of the obstetricians, the pregnant women understand well the indications for cesarean section. Following this same line, most of the pregnant women consider themselves rightly informed about the types of labor and the biggest source of information by them, maybe explain why there is the intention of performing natural birth, as reported, and with the advance of the gestation there is a change of plans, ending up with this expressive number of cesarean sections. This change of plans, initial intention of natural birth changed for C-section in the end of the gestation, is noticed by authors in recent researches [18]. These authors agree that further investigations are needed to analyze this phenomenon.

Referring to the information about the types of delivery of pregnant women and the transfer of such information to them, Potter et al. [26], Ossis et al. [27] e Hopkins [28] state that if pregnant women were well informed and enlightened about the types of delivery and the procedures to be performed, the number of cesarean sections would not be occurring at this rate.

Most of the obstetricians associated the pre-determined idea of many pregnant women who perform cesarean section with the fear of the pain and of the unexpected, the anesthesia in the C-section and influence of the family helps in this decision. The doctors notice a new way of seeing natural birth, there is a rejection, an inherent fear, as it can be confirmed by doctor E: "The culture of the patients that leads to fear of vaginal delivery." In fact, more than half of pregnant women showed fear with the possibility of vaginal delivery which was associated with the fear of natural birth pain. At the same time, more than half of the women perceived the possibility of performing the cesarean section smoothly due to analgesic that relieves pain. This contradiction can be seen and analyzed by the speech of the mother A.A.S. when she says: "People told me that the pain is huge". So initially the women prefer vaginal delivery, but the fear passed through her social group and family contain a burden of suffering and therefore the rejection of this type of delivery, which may make them rethink that possibility.

It can be argued that doctors could be more forceful in 
the definition of the type of labor, when patients with adequate conditions to perform normal birth opt for cesarean section, but is noticed an ethic, professional and financial dilemma retreated by the speech of doctor B: "In the case of private and health insurance, if I insist in normal delivery, I know I am going to lose the patient, because this have already happened with me in three cases".

It is noticed then, although more than half of the pregnant women who were interviewed decide for normal birth, the fear related to the pain is present in their conception. For the authors et al. [14], Faúndes et al. [24], Tedesco et al. [24], Bezerra e Cardoso [29] e Oliveira et al. [30], this fear is due to the lack of information and clarification of the pregnant women from doctors and another health professionals (nurses, psychologists) that do not priories during the assistance before the labor and during it, the solution of the doubts and to overcome the anxiety and insecurity of the women.

More than half of the obstetricians interviewed said that there is the difficulty in interacting with the pregnant woman regarding the decision on the type of delivery and that the relationship may even be broken, once the fear associated with the pain and the suffering of the pregnant woman related to the vaginal delivery contributes to the refusal of medical indication for this one, and opt for cesarean section.

Based on this, it is possible to infer that the majority of the obstetricians who participated in this study credited the pregnant women on the decision on what type of labor to be done. However, the survey held with the pregnant women showed that almost the totality of the pregnant women deposits confidence in the obstetrician to assist them on deciding the type of labor to be made, being in the hands of the doctor the final decision. Therefore, it appears not to have disagreements between the pregnant women and the physicians about the decision on the type of labor, as states the Doctor E: "The decision is always the responsibility of the doctor who may or not take suggestions”. The pregnant women follow the same line, at least in the beginning, they credit to the doctor the trust for the decision, trust based on the knowledge of the professional, as shown by the pregnant women A.F.B.: "The physician studied to guide me properly and he knows how it is evolving the labor". Despite this apparent unanimity, one can notice that a lot of interference in the gestational process does not lead to numbers which can be considered acceptable of normal deliveries and cesarean.

Regarding the considerations of the physicians who were interviewed, it has been questioned whether there should be freedom of choice by the woman. The question is whether this possibility comes associated with sufficient information to make this decision rounded on risks involving the cesarean section [31]. Some researchers have found in their work reasons to question that the increase in surgical deliveries must be attributed to the preference of women [32,33].

In the analysis of most of the data collected, there was disagreement between the information of the pregnant women and the obstetricians, situation already noticed by another authors [24,25]. The sides involved do not recognize themselves as responsible for the high number of caesarean sections, being required new approaches to the analysis. In this analysis, it is tried to realize what are the factors that lead the pregnant women and doctors who agree on crucial issues, how to prefer and endorse the normal delivery as the first desirable option, and that doctors are agents who should have the final decision on which type of delivery should be performed, to support this extreme result in the number of cesarean deliveries.

\section{REFERENCES}

[1] Faúndes, A. and Cecatti, J.G. (1991) The cesarean operation in Brazil. Incidence, trends, causes, consequences and proposals of action. Coronary Artery Disease of Public Health, 7, 150-173.

[2] Lane, E. and Gellerte, R. (1984) Cesarean. What is the acceptable incidence? Brazilian Journal of Gynecology, 94, 437-439.

[3] World Health Organization (1985) Appropriate technology for birth. Lancet, 2, 436-437.

[4] Latin American Center of Perinatology and Development. (1988) Cesarean birth today. Perinatal Health, 3, 101-108.

[5] Janowitz, B. (1982) Cesarean section in Brazil. Social Science and Medicine, 16, 19. doi:10.1016/0277-9536(82)90419-1

[6] Janowitz, B., Higgins, J.E., Clopton, D.C., Nakamura, M.S. and Brown, M.L. (1982) Access to postpartum sterilization in southeast Brazil. Medical Care, 20, 526-534. doi:10.1097/00005650-198205000-00009

[7] Guise, J.M., Hashima, J. and Osterweil, P. (2005) Evidence-based vaginal birth after cesarean section. Best Practice \& Research Clinical Obstetrics \& Gynaecology, 19, 117-130. doi:10.1016/j.bpobgyn.2004.10.015

[8] Morell, M.G.G. and Mello, A.V. (1995) The statement of live newborn in the State of São Paulo: Some results. Demographic Inform SEADE, 29, 201-331.

[9] Civil Society Family Welfare in Brazil (1996) Demographic and health national research. Rio de Janeiro, Bemfam, 1997.

[10] Rattner, D. (1996) About the hypothesis of stabilizing cesarean rates in the State of Sao Paulo, Brazil. Public Health Magazine, 30, 19-33.

[11] Barros, F.C. (1991) Epidemic of cesarean sections in Brazil. Lancet, 338, 167-169. doi:10.1016/0140-6736(91)90149-J

[12] Junior, J.C.S., Kunkel, N., Gomes, M.A. and Freitas, P.F. 
(2007) Inverse equity and disparities in access to technology in childbirth in Santa Catarina, Brazil, 2000-2004. Bras Health Mater Infant Magazine, 7, 397-403.

[13] Hotimsky, S.N., Rattner, D., Venancio, S.I., Bógus, C.M. and Miranda, M.M. (2002) Childbirth how I see... or as I wish? Expectations of pregnant women from SUS about childbirth and obstetric care. Coronary Artery Disease of Public Health, 18, 1303-1311.

[14] Barbosa, G.P., Giffin, K., Angulo-Tuesta, A., Gama, A.S., Chor, D., D’Orsi, E., et al. (2003) Caesarean section: Who desires it? Under what circumstances? Coronary Artery Disease of Public Health, 19, 1611-1620.

[15] Berquó, E. (1993) Brazil, Brazil, an exemplary case. Contraception and surgical births-Waiting for an exemplary action. Feminist Studies Magazine, 1, 366-381.

[16] (2008) Normal delivery: ANS and Health Ministry launches campaign.

http://www.ans.gov.br/portal/upload/noticias/ Hotsite Pa rto/clipping.html

[17] Oliveira, I. (2008) The "epidemic" of cesarean section. http://www.ans.gov.br/portal/upload/noticias/_Hotsite_Pa rto/clipping.html

[18] Dias, M.A.B., Domingues, R.M.S.M., Pereira, A.P.E., Fonseca, S.C., Gama, S.G.N., Filha, M.M.T., et al. (2008) Path of women in the definicion for cesarean labor: Case of study in two unities of the additional health system of Rio de Janeiro State. Science and Public Health, 13, 15211534.

[19] Callegari-Jacques, S.M. (2006) Organization of quantitative data. Biostatistics: Principles and Applications, Porto Alegre, Artmed, 19-25.

[20] Dias, M.A.B. and Deslandes, S.F. (2006) Expectations on the assistance to women in labor who are users of a public maternity ward of Rio de Janeiro, Brazil: The challenges of a public policy of humanization of assistance. Coronary Artery Disease of Public Health, 22, 2647-2655.

[21] Barros, A.J.D., Santos, I.S., Victora, C.G., Alnenaz, E.P., Domingues, M.R. and Timm, I.K. (2006) Birth cohort of Pelotas, 2004: Methodology and description. Public Health Magazine, 40, 402-413.

[22] Teixeira, N.Z.F. and Pereira, W.R. (2006) Hospital delivery -Experiences of women from the periphery of CuiabaMT. Bras Nursing Magazine, 59, 740-744.

[23] Carniel, E.F., Antonio, M.A.R.G.M., Mota, M.R.M.L., Morcillo, A.M. and Zanolli, M.L. (2003) The "declaration of newborn alive" guiding health actions at the local level. Bras Mater Infant Health Issues Magazine, 3, 165174.

[24] Faúndes, A., Pádua, K.S., Osis, M.J.D., Cacatti, J.G. and Sousa, M.H. (2004) Opinion of brazilian women and physicians about the preference on the delivery type. Public Health Magazine, 38, 488-494.

[25] Tedesco, R.P., Filho, N.L.M., Mathias, L., Benez, A.L., Castro, V.C.L., Bourroul, G.M., et al. (2004) Determinant factors to the first way pregnant women about the type of delivery. Bras Ginecological and Obstetric Magazine, 26 791-798.

[26] Potter, J.E., Berquó, E., Perpetuo, I.H.O., Leal, O.F., Hopkins, K., Souza, M.R., et al. (2001) Unwanted caesarean sections among public and private patients in Brazil: Prospective study. BMJ, 323, 1155-1158. doi:10.1136/bmj.323.7322.1155

[27] Osis, M.J., Pádua, K.S., Duarte, G.A., Souza, T.R. and Faúndes, A. (2001) The opinion of Brazilian women regarding vaginal labor and cesarean section. International Journal of Gynecology \& Obstetrics, 75, S59-S66. doi:10.1016/S0020-7292(01)00518-5

[28] Hopkins, K. (2000) Are Brazilian women really choosing to deliver by cesarean? Social Science \& Medicine, 51, 725-740. doi:10.1016/S0277-9536(99)00480-3

[29] Bezerra, M.G.A. and Cardoso, M.V.L.M. (2006) Cultural factors that interfere in the experiences of women during labor and birth. Latino-am Nursing Magazine, 14, 414421.

[30] Oliveira, S.M.J.V., Riesco, M.L.G., Miya, C.F.R. and Vidotto, P. (2002) Type of delivery: women's expectations. Latino-am Nursing Magazine, 10, 667-674.

[31] Mello e Souza, C. (1994) C-sections as ideal births: The cultural constructions of beneficence and patients' rights in Brazil. Cambridge Quarterly of Healthcare Ethics, 3, 358-366.

[32] Hopkins, K.L. (1998) Under the Knife: Cesarean section and the female sterilization in Brazil. Ph.D. Thesis, Austin, University of Texas.

[33] Perpétuo, I.H.O., Bessa, G.H. and Fonseca, M.C. (1998) Cesarean section: A perspective analysis of women from Belo Horizonte. XI Annual Meeting of the National Population Studies of the Brazilian Association of Population Studies.

http://www.abep.nepo.unicamp.br/docs/anais/PDF/1998/a 126.pdf 